\title{
O acesso à água e saneamento na promoção do desenvolvimento humano
}

Access to water and sanitation in promoting human development

Acceso al agua y al saneamiento en la promoción del desarrollo humano

Talita Bozon Penteado

Bolsista PIBIC/CNPq, PUC- Campinas, Brasil.

talitabozon@hotmail.com

Bruna Angela Branchi

Professora Doutora, PUC-Campinas, Brasil. bruna.branchi@puc-campinas.edu.br 


\title{
Revista Científica ANAP Brasil
}

\author{
ISSN 1984-3240 - Volume 14, número 35, 2021
}

\section{RESUMO}

A discussão sobre a provisão dos serviços de água e saneamento é de suma importância para entender o caráter multidimensional das desigualdades brasileiras. Estes serviços possuem uma ligação direta com a qualidade de vida e bem-estar da população. Ao serem reconhecidos como direito humano há uma mais clara intersecção com as esferas sociais. Neste artigo, por intermédio de uma pesquisa descritiva e exploratória, e da análise qualitativa dos dados disponíveis de água e saneamento, buscou-se entender a evolução e as precariedades persistentes no país, além de agregar um paralelo com o Índice de Desenvolvimento Humano (IDH). Nas últimas duas décadas houve um aumento da proporção de domicílios brasileiros com os serviços de água e esgotamento sanitário, mesmo que este último continue apresentando o maior déficit, mas continuam presentes relevantes diferenças regionais. Emblemático é o caso das regiões Norte e Nordeste que embora tenham registrado progressos não foram suficientes para alcançar os níveis de regiões mais desenvolvidas, como o Sudeste. Cruzando as informações sobre o IDH e os indicadores de acesso a estes serviços foi possível melhorar a descrição das desigualdades na qualidade de vida e identificar quais estados brasileiros necessitam melhorar os indicadores de abastecimento de água e esgoto, visando aprimorar o bem-estar da população.

PALAVRAS-CHAVE: Desigualdades. Qualidade de vida. Bem comum.

\section{ABSTRACT}

The discussion about the provision of water and sanitation services is of paramount importance to understand the multidimensional character of Brazilian inequalities. These services have a direct connection with the population's quality of life and well-being. By being recognized as a human right, there is a clearer intersection with the social spheres. In this article, through descriptive and exploratory research, and qualitative analysis of available data on water and sanitation, we sought to understand the evolution and persistent precariousness in the country, in addition to adding a parallel with the Human Development Index (HDI). In the last two decades there has been an increase in the proportion of Brazilian households with water and sewage services, even though the latter continues to show the greatest deficit, but relevant regional differences continue to be present. Emblematic is the case of the North and Northeast regions: despite having registered progress, it was not enough to reach the levels of more developed regions, such as the Southeast. By crossing the information on the HDI and the indicators of access to these services, it was possible to improve the description of inequalities in the quality of life and identify which Brazilian states need to improve water and sewage supply indicators, in order to improve the population's well-being.

KEYWORDS: Inequalities. Quality of life. Common goods.

\section{RESUMEN}

La discusión sobre la provisión de servicios de agua y saneamiento es de suma importancia para comprender el carácter multidimensional de las desigualdades brasileñas. Estos servicios tienen una conexión directa con la calidad de vida y el bienestar de la población. Al ser reconocido como un derecho humano, hay una intersección más clara con los ámbitos sociales. En este artículo, mediante de una investigación descriptiva y exploratoria, y un análisis cualitativo de los datos disponibles sobre agua y saneamiento, se buscó comprender la evolución y la precariedad persistente en el país, además de agregar un paralelo con el Índice de Desarrollo Humano (IDH). En las últimas dos décadas ha habido un aumento en la proporción de hogares brasileños con servicios de agua y alcantarillado, aunque este último sigue presentando el mayor déficit, pero siguen presentes diferencias regionales relevantes. Emblemático es el caso de las regiones Norte y Nordeste que, a pesar de haber registrado avances, no fueron suficientes para alcanzar los niveles de regiones más desarrolladas, como la Sureste. Al cruzar la información sobre el IDH y los indicadores de acceso a estos servicios, fue posible mejorar la descripción de las desigualdades en la calidad de vida e identificar qué estados brasileños necesitan mejorar los indicadores de abastecimiento de agua y alcantarillado, a fin de mejorar la situación de la población bienestar.

PALABRAS CLAVE: Desigualdades. Calidad de vida. Bien común. 


\section{Revista Científica ANAP Brasil}

ISSN 1984-3240 - Volume 14, número 35, 2021

\section{INTRODUÇÃO}

A provisão dos serviços de água e saneamento é delimitada por avanços e retrocessos (HELLER, 2009). A precariedade do acesso ao saneamento, simboliza um desinteresse no olhar da perspectiva social (RODRIGUES, 2019), e interfere diretamente em diversas facetas da vida humana.

O conceito de qualidade de vida tem caráter multidimensional, com dimensões subjetivas e objetivas. A Organização Mundial da Saúde (OMS) define a qualidade de vida como "as percepções dos indivíduos sobre sua posição na vida no contexto da cultura e sistemas de valores em que vivem e em relação aos seus objetivos, expectativas, padrões e preocupações" (OMS, 2012, p. 8, tradução nossa). Ao mesmo tempo há elementos objetivos que afetam o bemestar e a qualidade de vida. Por exemplo o local de moradia, a acessibilidade aos serviços de água e saneamento, a qualidade e continuidade deles, representam condições básicas para uma vida de qualidade. Assim como a qualidade do meio ambiente, que inclui a disponibilidade de recursos hídricos e o ar limpo, constituem elementos centrais para o bem-estar.

Em outras palavras, a qualidade de vida contém elementos que vão além da subjetividade individual, apontando para dimensões objetivas, observáveis e quantificáveis quais qualidade da água, número de domicílios conectados à rede de abastecimento de água e de esgoto sanitário (HERCULANO, 1998).

A OMS (2021) afirma que o acesso à água potável, saneamento e higiene estão na base do bem-estar dos indivíduos. Não se trata apenas de um pré-requisito para saúde, mas é uma condição essencial para a sobrevivência, frequência escolar e habilidade no trabalho.

A avaliação da qualidade de vida, especialmente numa abordagem multidimensional, atiçou o debate acadêmico e teve no Índice de Desenvolvimento Humano (IDH) um dos indicadores mais usados hoje em dia. Beneficiado pela contribuição acadêmica de Amartya Sen (2010) e pela metodologia proposta pelo Programa das Nações Unidas para o Desenvolvimento (PNUD), o IDH sintetiza em um número índice três dimensões fundamentais para o bem-estar: saúde, educação e renda (UNDP, 2018).

As carências em saneamento impactam diretamente sobre a saúde e qualidade de vida da população. De acordo com a OMS (1946), a saúde é um estado de pleno bem-estar físico, mental e social. A falta de água tratada e dos serviços de coleta e tratamento de esgoto são responsáveis por uma parte das infecções gastrointestinais. Os estudos do Instituto Trata Brasil, em colaboração com a Fundação Getúlio Vargas, mostram que os municípios com maior atendimento à coleta de esgoto possuem menor incidência de infecções gastrointestinais, principalmente em crianças e jovens até 14 anos (FGV; TRATA, 2010).

O relatório Benefícios Econômicos e Sociais da Expansão do Saneamento no Brasil, do Instituto Trata Brasil (MAGNABOSCO; FREITAS, 2018) adverte que existem dois problemas ligados a falta do saneamento que causam custos irrecuperáveis para a sociedade: (1) o aumento de infeções, afasta as pessoas de atividades laborais, custando a sociedade com horas não trabalhadas; e, (2) despesas públicas e privadas ascendem a vista da necessidade de tratamento das pessoas infectadas.

Ademais, o mercado de trabalho e as atividades econômicas também são impactados, ao passo que a produtividade do trabalho e o desempenho de estudantes diminuem pela falta de saneamento e, no longo prazo, incide sobre a renda familiar. Em outras palavras, trabalhadores suscetíveis a determinadas infecções/doenças, desenvolvem uma saúde precária, 


\section{Revista Científica ANAP Brasil}

ISSN 1984-3240 - Volume 14, número 35, 2021

afetando sua produtividade, impactando no desenvolvimento de suas carreiras, e no potencial de renda; assim como, à medida que crianças e jovens são infectados, estes são afastados das atividades escolares, afetando tanto o desempenho educacional, como, o desempenho laboral, no longo prazo (MAGNABOSCO; FREITAS, 2018).

Além destes aspectos sociais e econômicos, a carência na coleta e tratamento dos esgotos é uma das principais causas dos desequilíbrios ambientais, ao passo que, a negligência destes serviços promove: poluição de rios e lagos receptores, e de outros efluentes, bem como, colabora na transmissão de doenças, onerando os gastos com a saúde e as futuras gerações. É importante destacar também que tais efeitos também são produtos da baixa qualidade destes serviços (KUWAJIMA et al., 2020).

Uma recente pesquisa do IPEA identificou uma correlação positiva entre os indicadores de atendimento de água e esgotamento sanitário e o Índice de Vulnerabilidade Social (KUWAJIMA et al., 2020). Este último é um indicador constituído por três dimensões: infraestrutura urbana, capital humano, e renda e trabalho, responsável por expressar as desigualdades sociais. A pesquisa apontou que municípios que possuem maior déficit de água e esgotamento apresentaram maiores índices de vulnerabilidade social. Neste sentido, é possível concluir que as carências deste serviço estão diretamente relacionadas com as diferentes facetas das desigualdades, assim como nas questões sociais, econômicas e de saúde pública.

A seguir, com diligência, abordamos a discussão da natureza da água e saneamento com a finalidade de mostrar que as diferentes interpretações (bem público de valor econômico e direito humano) impactam na garantia do acesso universal a estes serviços.

A água está na interseç̧ão entre bem comum e bem econômico, discussão de suma importância para compreender os debates em torno de sua disponibilidade e acessibilidade (RODRIGUES, 2019). De acordo com Ostrom et al. (1994), a definição de bens comuns abrange uma classe de bens que contemplam dois critérios: subtractability, ou seja, o uso de determinado recurso/benefício por um indivíduo, subtrai a quantidade disponível para outros; e exclusion, refere-se em termos de facilidade ou dificuldade de excluir ou limitar potenciais usuários para consumir determinado bem.

Logo, bens econômicos são aqueles que possuem uma precificação e majoritariamente são classificados como escassos. Na perspectiva da água, existe um paradoxo, pois é reconhecido como um bem público dotado de valor econômico, comportando como um ativo vulnerável à mercantilização, assim, "a água encaixa-se em algum lugar entre dois extremos, bem público e bem privado" (ZUFFO; ZUFFO, 2016, p. 13).

No Brasil, a Lei n. 9.433 de 1997 instituiu a Política Nacional de Recursos Hídricos, e em seu Artigo 1ํ, nos incisos I e II: reconhece a água como um bem de domínio público, bem como é um recurso natural limitado, dotado de valor econômico. No Dublin Statement on Water and Sustainable Development de 1992 (WMO, 1992) a água foi reconhecida como bem econômico, destacando que sua administração, consequentemente, passaria a ter um caráter equânime incorporando mais preservação.

Logo, a Lei n. 11.445 de 2007 estabelece as diretrizes nacionais para o saneamento básico e em seu artigo 20 estabelece a universalização do acesso e efetiva prestação deste serviço. Neste sentido, o seu reconhecimento como direito humano permitiu ampliar a visão econômica limitante, afirmando a necessidade de uma abordagem holística para seu gerenciamento, incluindo o desenvolvimento social, econômico e proteção dos ecossistemas. 
Deste modo, à luz de um caráter multidimensional das desigualdades, sucedeu a necessidade de discutir o acesso à água e ao saneamento básico a partir de uma visão holística a fim de entender os avanços e as debilidades persistentes na provisão destes serviços no Brasil. Outrossim, a análise a posteriori contempla além dos indicadores de água e saneamento, o índice de desenvolvimento humano, ao passo que, que tais serviços foram reconhecidos como direitos humanos, permitindo agregar uma visão holística ao seu tratamento, aglutinando questões sociais, como garantia de acesso aos excluídos e restrição ao mercado das águas.

\section{OBJETIVO}

A pesquisa tem como objetivo principal é estudar a evolução do acesso à água potável e ao saneamento básicos no Brasil nos anos 2000. Com este estudo será possível avaliar os desafios que ainda persistem para assegurar o acesso universal a estes serviços, como preconizado pelo sexto Objetivo de Desenvolvimento Sustentável, assim como complementar os indicadores de bem-estar incluindo uma dimensão essencial para a qualidade de vida qual é o acesso à água e ao esgoto sanitário.

\section{METODOLOGIA}

Trata-se de uma pesquisa qualitativa, de tipo exploratório e descritivo. É uma pesquisa exploratória porque tem como objetivo proporcionar maior familiaridade com o objeto de estudo. É descritiva no sentido que a investigação atenta a analisar, registrar e relacionar diferentes variáveis com o fenômeno objeto de estudo (CERVO; BERVIAN; SILVA, 2006; MARCONI; LAKATOS, 2017).

Pelo procedimento usado, trata-se de uma pesquisa bibliográfica e documental. Os dados usados são fornecidos pelo Sistema Nacional de Informações sobre o saneamento básico (SNIS) e pelo Atlas de Desenvolvimento Humano.

O SNIS é uma base de dados com informações e indicadores acerca de serviços de água e esgoto, bem como manejo de resíduos sólidos urbanos e drenagem e manejo das águas pluviais urbanas. É atualizado anualmente através da coleta de dados dos municípios e prestadores de serviços de saneamento (SNIS, 2020).

Para atingir os objetivos da pesquisa foram selecionados 4 indicadores do SNIS, cuja evolução foi examinada ao longo do período 2001- 2019 para o Brasil e suas grandes regiões. Os indicadores selecionados estão descritos no quadro 1.

Quadro 1: Indicadores selecionados, siglas e definições.

\begin{tabular}{|c|c|c|}
\hline Sigla & Nome & Definição \\
\hline IN055 & Índice de atendimento total de água & $\begin{array}{c}\text { Valor da população total atendida com abastecimento de água pelo prestador de } \\
\text { serviços, no último dia do ano de referência. Corresponde à população urbana que é } \\
\text { efetivamente atendida com os serviços acrescida de outras populações atendidas } \\
\text { localizadas em áreas não consideradas urbanas. }\end{array}$ \\
\hline IN023 & Índice de atendimento urbano de água & $\begin{array}{c}\text { Valor da população urbana atendida com abastecimento de água pelo prestador de } \\
\text { serviços, no último dia do ano de referência. Corresponde à população urbana que é } \\
\text { efetivamente atendida com os serviços. }\end{array}$ \\
\hline IN056 & $\begin{array}{c}\text { Índice de atendimento total de esgoto referido aos } \\
\text { municípios atendidos com água }\end{array}$ & $\begin{array}{c}\text { Valor da população total atendida com esgotamento sanitário pelo prestador de } \\
\text { serviços, no último dia do ano de referência. Corresponde à população urbana que é } \\
\text { efetivamente atendida com os serviços acrescida de outras populações atendidas } \\
\text { localizadas em áreas não consideradas urbanas. }\end{array}$ \\
\hline & $\begin{array}{c}\text { Índice de atendimento urbano de esgoto referido } \\
\text { aos municípios atendidos com água }\end{array}$ & $\begin{array}{l}\text { Valor da população urbana beneficiada com esgotamento sanitário pelo prestador } \\
\text { de serviços, no último dia do ano de referência. Corresponde à população urbana } \\
\text { que é efetivamente atendida com os serviços. }\end{array}$ \\
\hline
\end{tabular}

Fonte: Glossário de Informações- Água e Esgoto (SNIS, 2018). 


\section{Revista Científica ANAP Brasil}

ISSN 1984-3240 - Volume 14, número 35, 2021

A análise da qualidade de vida foi realizada comparando as Unidades da Federação nos anos 2000 e 2017 usando o IDH e os indicadores descritos no quadro 1.

O IDH inclui três dimensões relevantes para avaliar o bem-estar, quais renda, escolaridade e saúde. Incluindo as dimensões de acesso à água e esgotamento sanitário é possível enriquecer a análise e obter um quadro mais completo das condições de vida da população brasileira.

\section{ANÁLISE DOS RESULTADOS}

\subsection{A evolução do acesso à água e saneamento nos anos 2000}

A análise da evolução do acesso à água e ao saneamento nos anos 2000 denota a discrepância no acesso dos serviços de água em relação ao saneamento, sendo que o primeiro, de maneira geral no país, tem uma maior cobertura.

Outrossim, a primeira análise das regiões demonstrou as disparidades no atendimento destes serviços, direcionando a pesquisa à um entendimento mais aprofundado $\mathrm{e}$ detalhado por Unidade da Federação (UF) em conjunto com o indicador de desenvolvimento humano. A resultante desta investigação é coerente ao que Heller (2009) descreve sobre o Brasil, dado que, as inconsistências das políticas governamentais assinalam a limitação do abastecimento de água e saneamento das populações periféricas urbanas e rurais, principalmente.

Em média, no Brasil, em 2019 84\% dos domicílios se beneficiavam com o serviço de abastecimento de água, com um aumento de aproximadamente 5 p. p. desde 2001 (Figura 1). Trata-se de população urbana e rural que se beneficia do serviço de abastecimento de água potável. De acordo com a lei no 11.448/2007, atualizada pela lei no 14.026/2020, este serviço "é constituído pelas atividades e pela disponibilização e manutenção de infraestruturas e instalações operacionais necessárias ao abastecimento público de água potável, desde a captação até as ligações prediais e seus instrumentos de medição" (BRASIL, 2020). As regiões com menor atendimento são as regiões Norte e Nordeste. E ambas, mais o Centro-Oeste, têm suas médias abaixo da média brasileira em todos os anos.

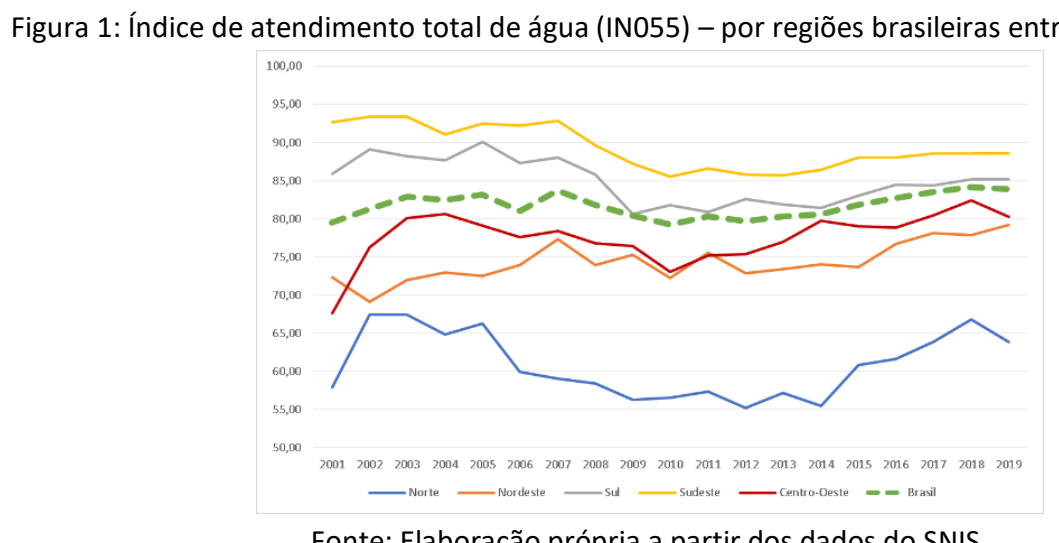

Fonte: Elaboração própria a partir dos dados do SNIS.

A região Norte, mesmo avançando aproximadamente 6 pontos percentuais, é a região com os piores resultados deste índice. Nota-se que, após um forte aumento (10 p.p.) nos 


\section{Revista Científica ANAP Brasil}

ISSN 1984-3240 - Volume 14, número 35, 2021

primeiros anos da análise, a sofreu uma queda continua até 2014. A recuperação seguinte não permitiu voltar aos valores de início dos anos 2000: em 2019 ficou em 63,87\% contra o 69,16\% de 2002. Ou seja, podemos deduzir que houve aumento populacional não acompanhado pela expansão da rede deste serviço.

O Nordeste entre 2001 e 2019 avançou quase 7 pontos percentuais. Mas o destaque está para o Centro-Oeste que saltou quase 13 pontos percentuais, atingindo em 2019 80\% dos municípios com atendimento de água. Detalhe para o fato que mesmo em 2001 o Nordeste estava com resultados melhores que o Centro-Oeste, este último em 2019 é que apresentou vantagens.

Neste índice pode-se observar um comportamento semelhante entre 2000 e 2005 nas regiões Norte e Centro-Oeste, pois houve um pico seguido por um declínio, este último mais acentuado no Norte, na \% da população com abastecimento de água.

O Sul, apesar de pequenas variações percentuais, alcançou 2019 com o mesmo resultado (com pequenas diferenças percentuais) de 2001, ou seja, não se observa avanços, mas mesmo em 2009 tendo uma queda de 5 pontos percentuais, recuperou-se. O Sudeste é a região brasileira com os melhores resultados do índice, mas nota-se uma queda de 4 pontos percentuais do índice em 2019, quando comparado ao primeiro ano de análise.

O índice de atendimento urbano de água no Brasil, em média, alcança resultados positivos, acima de $90 \%$. O Nordeste e Norte ainda continuam abaixo da média brasileira (Figura 2).

Figura 2: Índice de atendimento urbano de água (INO23) - por regiões brasileiras entre 2000 e 2019 (\%)

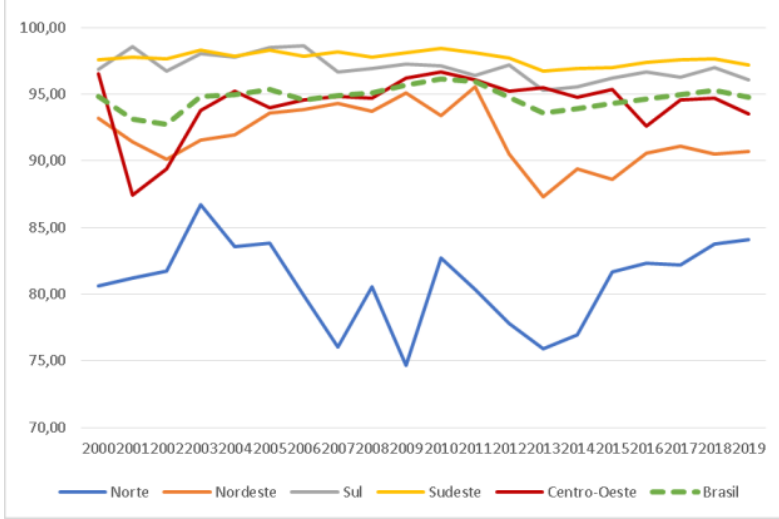

Fonte: Elaboração própria a partir dos dados do SNIS.

O Norte é a região brasileira que avançou aproximadamente 4 pontos percentuais nos anos analisados, entretanto, o índice, como é possível analisar graficamente, sofre alterações ao longo dos anos, sendo que em 2003, atingiu seu melhor resultado em 86,72, mas em 2009 atingiu 74,65, logo, a partir de 2013 demonstra um comportamento constante de crescimento, atingindo 84,08 em 2019. O Nordeste sofreu uma retração de 3 pontos percentuais nos anos analisados, sendo sua maior queda pode ser vista entre 2011 e 2012 em cinco pontos percentuais.

O Centro-Oeste também teve uma queda de três pontos percentuais ao analisar 2000 e 2019, mas é uma região que contempla cerca de $94 \%$ da sua população urbana com atendimento de água, é possível observar uma queda de quase 10 pontos percentuais entre 2000 e 2001, entretanto a partir de 2002 os resultados da região foram crescentes. 


\section{Revista Científica ANAP Brasil}

ISSN 1984-3240 - Volume 14, número 35, 2021

O Sul e o Sudeste foram as regiões que apresentaram os melhores resultados e com maior constância entre os anos analisados, portanto, não se observam avanços nem recuos nestas regiões, mantendo praticamente os mesmos resultados entre 2000 e 2019. Destaque para o sudeste que possui $97 \%$ de sua população urbana atendida com água.

Como pode ser observado na Figura 3, no Brasil em média somente $66 \%$ da população está se beneficiando do atendimento de água e esgoto, com um aumento de 8 p.p. ao longo do período 2001-2019. O Sudeste se destaca por ser a única região que sempre este acima da média nacional (79\% em 2019). A Região Norte continua apresentando os menores índices, chegando a $23 \%$ em 2019.

Figura 3: Índice de atendimento total de esgoto referido aos municípios atendidos com água (IN056) - por regiões brasileiras entre 2001 e 2019 (\%)

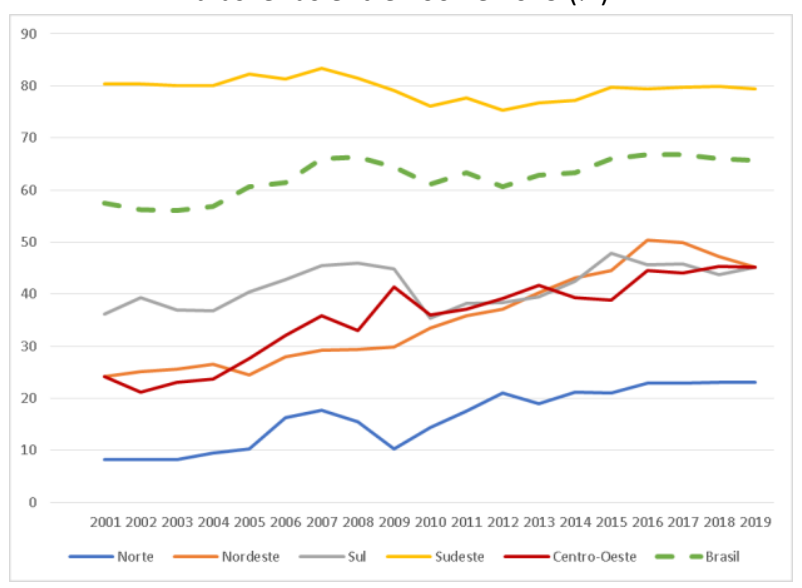

Fonte: Elaboração própria a partir dos dados do SNIS.

A Região Nordeste registrou um rápido crescimento de 21 p.p., se aproximando ao nível da Região Sul, de $24 \%$ para $45 \%$ e de $36 \%$ para $45 \%$ respectivamente. O Centro-Oeste avançou significativamente 21 pontos percentuais, passando de $24 \%$ para $45 \%$.

$\mathrm{Na}$ Figura 4 observa-se que o índice de atendimento urbano tem resultados superiores que o total. O Brasil neste índice tem em média $80 \%$ de sua população total atendida com esgoto e água, ademais, sofreu um aumento de aproximadamente 15 pontos percentuais entre $2000 \mathrm{e}$ 2019.

Figura 4: Índice de atendimento urbano de esgoto referido aos municípios atendidos com água (IN024) - por regiões brasileiras entre 2000 e 2019 (\%)

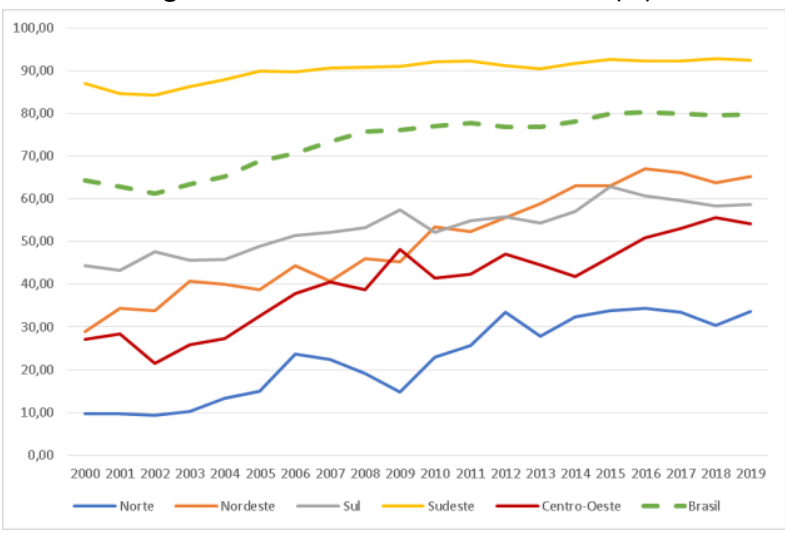

Fonte: Elaboração própria a partir dos dados do SNIS. 


\section{Revista Científica ANAP Brasil}

ISSN 1984-3240 - Volume 14, número 35, 2021

Novamente o Sudeste se destaca por resultados superiores à média brasileira e das outras regiões, em 2000 a região já atendia $87 \%$ de sua população passando para 92\% em 2019 - não se observam tantas variações, dados apontam somente para uma progressão e constância, diferente das outras regiões.

Norte, Nordeste, Sul e Centro-Oeste apresentaram em 2019, resultados superiores ao de 2000. O Norte continua sendo a mais carente nos termos de água e esgoto urbano, mas que avançou 23 pontos percentuais, passando entre 2000-2019 de 9,75 para 33,69.

O Nordeste fora a região com o maior avanço, de 36 pontos percentuais, alcançando níveis superiores ao Sul no último ano analisado. O Nordeste avançou de 29 para 65\%, e o Sul de 44 para $58 \%$. O Centro- Oeste aumentou aproximadamente 27 pontos percentuais, atingindo $54 \%$ da sua população urbana com esgotamento sanitário e água, entretanto, esta região fica somente atrás do Norte com $33 \%$.

\subsection{Uma análise das múltiplas desigualdades nos estados brasileiros}

Água e saneamento são significativos para o alcance do desenvolvimento humano. 0 Brasil é afetado pelas diversas facetas das desigualdades, como por exemplo, de renda, na qual galgou avanços, nos últimos anos, através de programas de distribuição de renda, como o Bolsa Família. Entretanto, observa-se que o atendimento de água e esgoto ainda são carências entre as políticas públicas nas UFs brasileiras. A seguir, identificamos através de um mapa de radar as conexões entre IDH e saneamento básico, e ao decorrer, construímos uma análise geral e inferências sobre os possíveis resultados do próximo cálculo do IDH.

\subsubsection{Região Norte}

A Figura 5 permite identificar uma mudança importante com uma melhora regional nos indicadores de esgoto, mesmo que o atendimento continue inferior ao de água. As UF que mais se destacaram neste sentido foram Roraima e Tocantins. O Amapá continua registrando as maiores carências relacionadas aos serviços de água e esgoto.

Os Estados da região Norte apontam para um desenvolvimento humano médio, e, somente Rondônia e Amazonas detêm um desenvolvimento humano alto, em 2010. Já em 2017, todas as UFs alcançaram ao nível alto. O progresso registrado pelo IDH interessou todas as UF da Região Norte, mantendo a Rondônia na melhor posição. Porém, quando incluímos a análise dos indicadores de água e esgoto o quadro descrito pelo IDH pode sofrer mudanças interessantes.

Emblemático é o caso de Rondônia onde o bom resultado do IDH não foi acompanhado pela evolução dos indicadores de água e esgoto, que em geral pioraram entre 2010 e 2017, tendo como única exceção o IN055. Pode ser que os avanços registrados na oferta de serviços de água e esgoto que melhoram as condições de saúde e de vida da população beneficiada demorem ainda algum tempo para serem capturados no IDH. 


\section{Revista Científica ANAP Brasil}

ISSN 1984-3240 - Volume 14, número 35, 2021

Figura 5: IDH e índices selecionados de água e saneamento básico das UFs da Região Norte, 2010 e 2017.

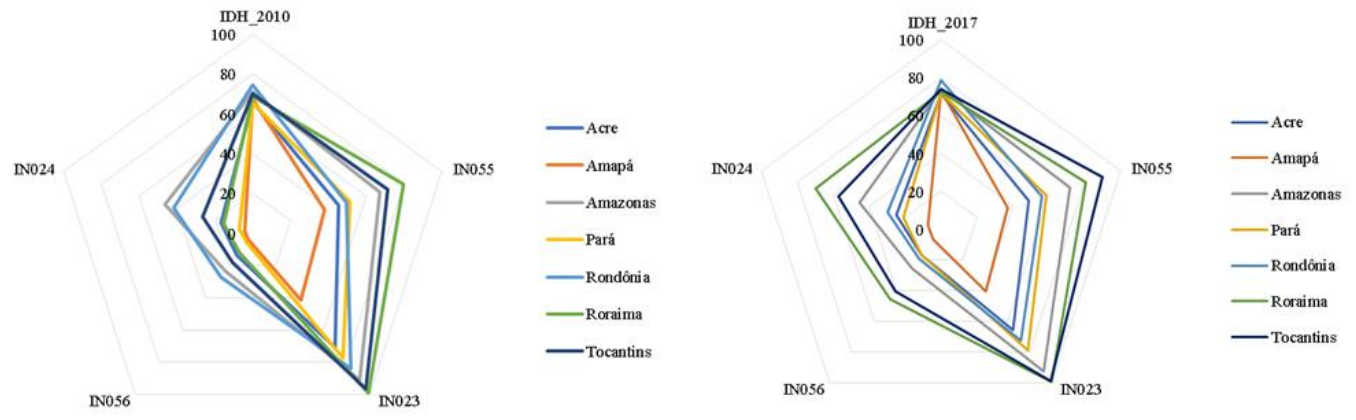

Legenda:

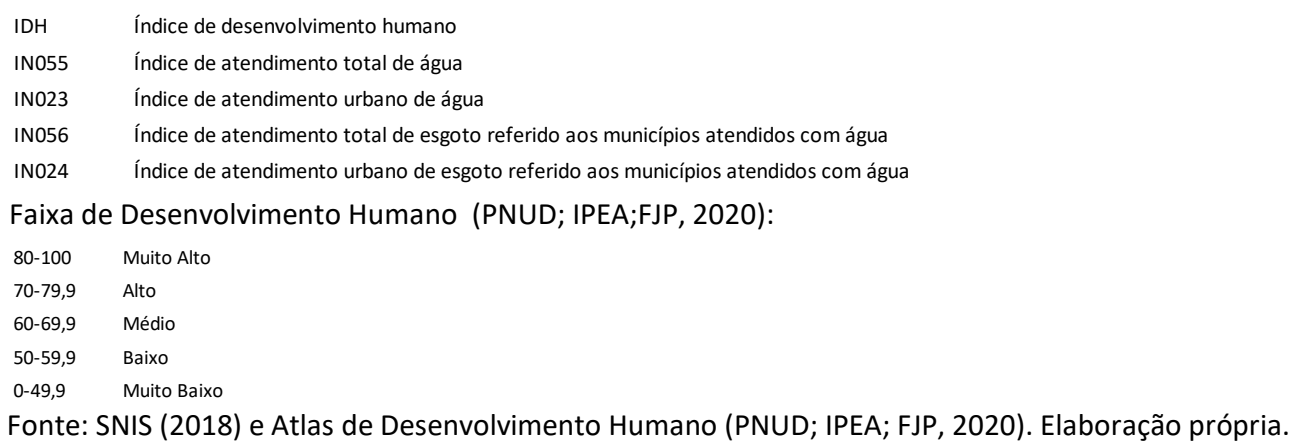

\subsubsection{Região Nordeste}

Na região Nordeste prevalece um nível médio de desenvolvimento humano em 2010, com exceção de Paraíba e Sergipe, que é alto. A situação se inverte em 2017, quando somente Maranhão, Pernambuco e Alagoas não alcançam o nível alto de desenvolvimento humano. A melhora do desenvolvimento humano foi acompanhada por uma melhora dos indicadores de água e esgoto, mesmo permanecendo uma forte heterogeneidade intrarregional (Figura 6).

Por exemplo, os estados de Piauí e Bahia foram os que mais avançaram em termos de desenvolvimento humano (5,4 p.p), mas apresentaram recuo somente em um dos indicadores, o de atendimento urbano de água. No atendimento total de água, o Piauí também apresentou o maior avanço entre as UFs de 10 p.p.; e avançou, aproximadamente 20 p.p. no atendimento total de esgoto, assim como, no atendimento urbano. A Bahia, assinalou um avanço significativo no IN056, em 11 p.p.

Figura 6: IDH e índices selecionados de água e saneamento básico das UFs da Região Nordeste, 2010 e 2017.

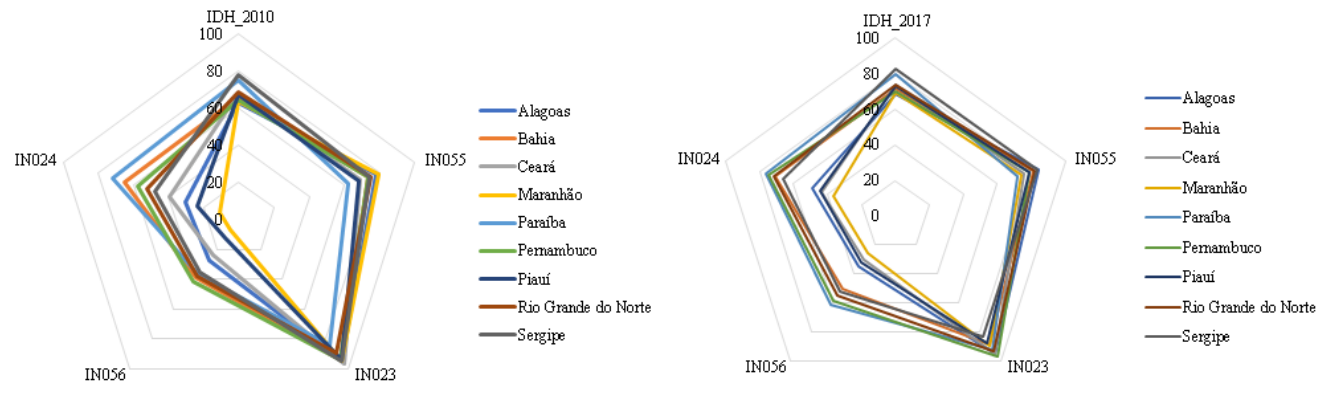

Fonte: SNIS (2018) e Atlas de Desenvolvimento Humano (PNUD; IPEA; FJP, 2020). Elaboração própria.

Nesta análise vale destacar que Sergipe é a UF com o maior IDH da região nos dois anos analisados, e mesmo tendo resultados positivos no restante dos indicadores, o 


\section{Revista Científica ANAP Brasil}

ISSN 1984-3240 - Volume 14, número 35, 2021

atendimento ao esgoto está em níveis médios em 2010. Logo, em 2017, com exceção ao indicador de atendimento urbano de água que decresceu 11 p.p, fora a UF com avanços significativos nos outros três indicadores-IN055, IN056 e IN024- em: 8,9 p.p, 17 p.p, e 18,5 p.p, respectivamente. Em outras palavras, mesmo contemplando os melhores índices de IDH, diminuiu o atendimento urbano ao serviço de água assinalando, portanto, uma piora da qualidade de vida da população urbana, mesmo que tinha acontecido avanços em outros indicadores.

Em geral, nos indicadores de atendimento de esgoto nenhuma das UFs apresentaram recuo. No atendimento total de esgoto, a Paraíba evoluiu, aproximadamente, 25 p.p., e, isso significa somente $61 \%$ da população, e vale destacar, que é a UF nordestina com o maior atendimento. Ademais, mesmo o Maranhão avançando nestes termos, aproximadamente, 19 p.p., continua sendo a UF com a menor cobertura deste serviço, $25 \%$ da população, assim como, contemplou o maior avanço em 25 p.p. no atendimento urbano, porém, é o pior resultado da região neste indicador (36\%).

Em suma, o atendimento de água, principalmente urbano, não é uma grave carência na região, e, não teve grandes avanços, porém houve piora em algumas UFs. Paradoxalmente, o atendimento de esgoto é deficiente, mas fora o que contemplou maiores avanços dentro do período analisado. $\mathrm{O}$ aumento do IDH nesta região pode ser visto como uma repercussão do aumento do atendimento do esgoto (total e urbano), e também de água total (que somente o Maranhão recuou).

\subsubsection{Região Centro-Oeste}

A região Centro-Oeste possui, em geral, um índice de desenvolvimento humano alto, e destaca-se o Distrito Federal como muito alto, em ambos os anos analisados-vale ressaltar que o Distrito Federal sempre será a exceção da região. A UF que mais avançou em seu IDH, foi o Mato Grosso do Sul (4,9 p.p.) (Figura 7).

Por ser um distrito, nota-se que o DF contempla em todos os índices resultados positivos e, preenche o gráfico praticamente em um pentágono, mas podemos observar, um resultado interessante: o DF apresentou recuou em todos os indicadores de água e esgoto, com destaque ao atendimento urbano de esgoto (11 p.p.). Uma possível justificativa para isto é o fato que, em 2010 o DF tinha 2,56 milhões de habitantes, em 2017 eram 3,04 milhões, um aumento de mais de $18 \%$, ou seja, os serviços de água e esgoto não acompanharam o crescimento populacional.

Figura 7: IDH e índices selecionados de água e saneamento básico das UFs da Região Centro-Oeste, 2010 e 2017.
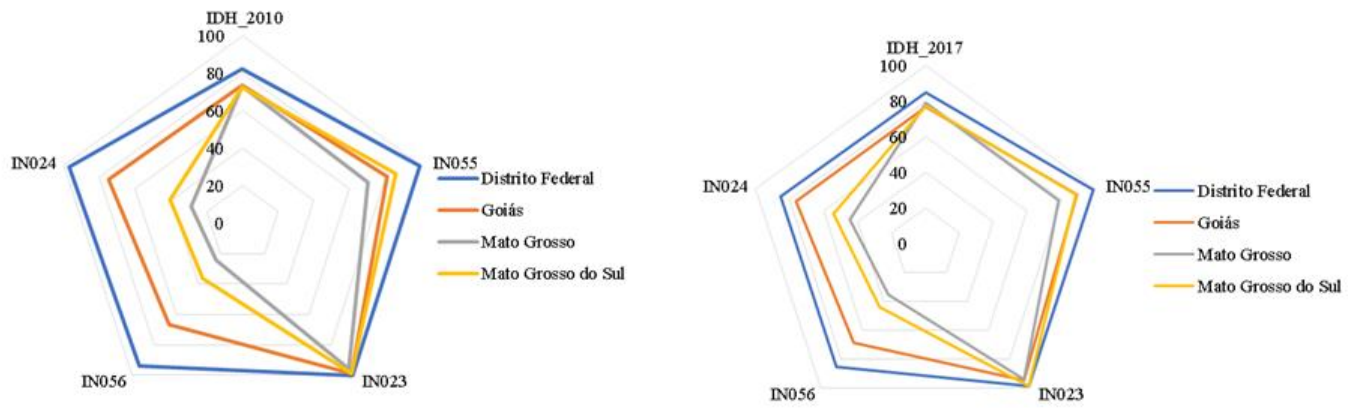

Fonte: SNIS (2018) e Atlas de Desenvolvimento Humano (PNUD; IPEA; FJP, 2020). Elaboração própria. 


\section{Revista Científica ANAP Brasil}

ISSN 1984-3240 - Volume 14, número 35, 2021

Em termos de atendimento total de água, a região está em níveis bons. Goiás e Mato Grosso foram as UFs com maior avanço (8 p.p.). Em termos de atendimento urbano de água, todas UFs sofreram um recuo, em pequenas proporções, logo, Goiás se destaca neste indicador, mas agora, de maneira negativa, visto que foi a UF com maior decréscimo (4 p.p.), entretanto, 94\% de sua população é atendida com este serviço.

Em relação ao atendimento de esgoto, o total, ainda assinala algumas carências, visto que Mato Grosso do Sul e Mato Grosso, mesmo com avanços significativos de 7,6 e 11 p.p, respectivamente, nas duas UFs o serviço de esgoto atende a menos da metade da população. 0 atendimento de esgoto urbano obteve avanços significativos no Mato Grosso e Mato Grosso do Sul, assim como no IN056; entretanto, mesmo que o Mato Grosso seja destaque em um salto de, quase, 16 p.p, continua sendo a UF mais carente deste serviço, sendo que somente $44 \%$ da população urbana é contemplada. Entre as 3 UFs da região, em ambos os anos Goiás contempla os melhores resultados, mas Mato Grosso e Mato Grosso do Sul avançam principalmente em termos de atendimento de esgoto.

\subsubsection{Região Sudeste}

As UFs da região Sudeste do país apresentam, em geral, um índice de desenvolvimento humano alto, somente em 2010, São Paulo apresentava nível médio. Mesmo apresentando resultados positivos para os 4 indicadores de atendimento de água e esgoto. Os indicadores de água - IN055 e IN023 - são em geral os melhores (Figura 8).

Figura 8: IDH e índices selecionados de água e saneamento básico das UFs da Região Sudeste, 2010 e 2017.
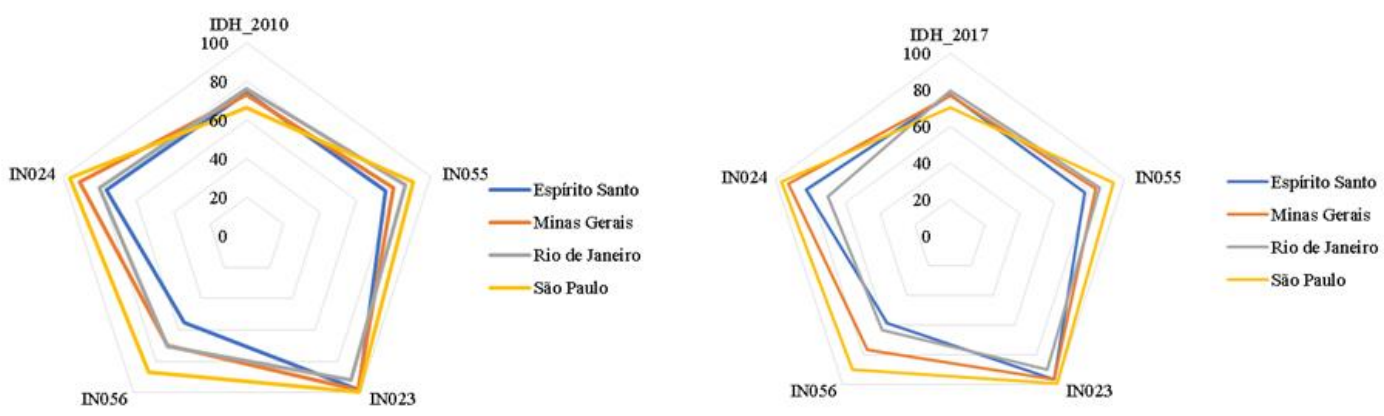

Fonte: SNIS (2018) e Atlas de Desenvolvimento Humano (PNUD; IPEA; FJP, 2020). Elaboração própria.

Em todas os indicadores, São Paulo se destaca com os melhores resultados, e, mesmo atingindo grande parte da sua população, este avança em termos significativos, principalmente no atendimento total de água e total de esgoto (ascendeu, aproximadamente, 3.3 p.p., em cada). Ainda sob uma perspectiva geral, é interessante notar, que mesmo com um avanço de seu IDH, e estabilidade no atendimento total de água, o Rio de Janeiro, recuou em todas os demais indicadores. Com exceção de São Paulo, todas as UFs do Sudeste sofreram um recuo no atendimento urbano de água, entretanto, estas permanecem cobrindo mais de $90 \%$ de sua população.

Quanto ao atendimento total de esgoto, Minas Gerais avançou em quase 7p.p., e o Espírito Santo mesmo crescendo em 3,2 p.p., permaneceu a UF mais carente da região, sendo que, somente $59 \%$ da população total é atendida com o esgoto. $O$ atendimento urbano de esgoto do Rio de Janeiro recuou 10 p.p., e passou a atingir somente $70 \%$ da população, 


\section{Revista Científica ANAP Brasil}

ISSN 1984-3240 - Volume 14, número 35, 2021

enquanto, o Espírito Santo, foi a UF com maior avanço, de 5.8 p.p, mas com a menor cobertura quando comparadas com as outras UFs, $82 \%$.

Em síntese, São Paulo é a UF de destaque nesta região, contempla os melhores resultados em todos os indicadores. Logo, o Rio de Janeiro, mesmo contemplando bons resultados nos indicadores, é a UF que recuo nos anos analisados em todos os indicadores, exceção somente para o IN055, que se manteve estável.

\subsubsection{Região Sul}

A análise da região Sul reflete uma heterogeneidade entre suas UFs. Paraná que tem o menor IDH do grupo apresenta os melhores indicadores de água e esgoto, que melhoraram no período, favorecendo uma avaliação do desenvolvimento humano mais equilibrada do que RGS e SC. O índice de desenvolvimento humano para o Paraná, é médio; para o Rio Grande do Sul é alto; e, para Santa Catarina passou de alto, para muito alto. Assim como as regiões do Norte - não nas mesmas proporções - a região Sul apresenta carências no atendimento de esgoto (Figura 9).

Figura 9: IDH e índices selecionados de água e saneamento básico das UFs da Região Sul, 2010 e 2017.
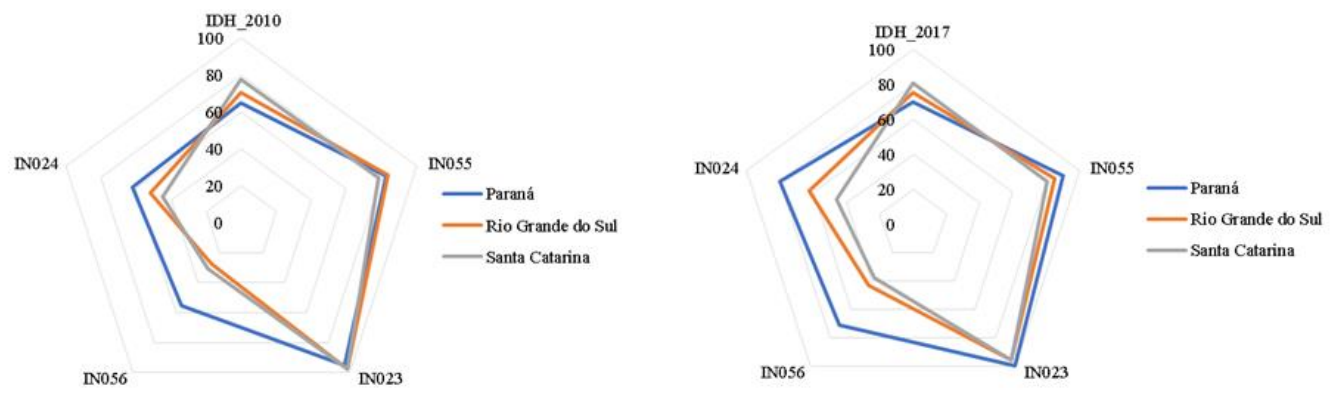

Fonte: SNIS (2018) e Atlas de Desenvolvimento Humano (PNUD; IPEA; FJP, 2020). Elaboração própria.

Neste ponto temos um resultado interessante, ao passo que, o Paraná, que tem o menor IDH da região, foi o que mais avançou, e, continua sendo a UF com os melhores resultados de atendimento total e urbano de esgoto, e ainda nestes, avançou 16 e 18 p.p, respectivamente - ademais, é a UF com maior cobertura em termos de atendimento de água também. Santa Cataria e Rio Grande do Sul mesmo avançando positivamente, ainda não contemplam nem metade de sua população total com o atendimento ao esgoto.

No atendimento urbano de água, os resultados da região são um pouco melhores do que ao total, entretanto, Santa Catarina mesmo contemplando menos da metade de sua população em 2010 (45\%), em 2017, cresce somente cerca de 1 p.p. Em contrapartida, o Paraná alcança $80 \%$ da sua população e o Rio Grande do Sul, avançou 10 p.p, chegando em $62 \%$ da população, um bom resultado, mas ainda pode-se notar carências.

No atendimento total de água, todas as UFs avançaram, com destaque novamente para o aumento significativo do Paraná; um resultado interessante é que está UF (Paraná) passou a contemplar o maior nível de atendimento (90\%) entre as UFs da região em 2017, ocupando o lugar que em 2010, permanecia do Rio Grande do Sul.

A heterogeneidade desta região evidencia a importância de olharmos para as múltiplas dimensões das desigualdades. As diversas facetas do desenvolvimento humano sinalizam que o cálculo do IDH é importante, mas ao incluirmos e compararmos este com os indicadores de água 


\section{Revista Científica ANAP Brasil}

ISSN 1984-3240 - Volume 14, número 35, 2021

e esgoto nos permite analisar sobre um quadro total da qualidade de vida. Ou seja, mesmo que RGS e SC tenham valores do IDH superiores ao comparamos com o Paraná, este indicador acaba ocultando outras condições - como a situação da água e esgoto - que, normalmente impactam no IDH no longo prazo.

\section{CONSIDERAÇÕES FINAIS}

Apesar dos avanços no atendimento destes serviços, o desafio persistente para assegurar este direito para todos é o esgotamento sanitário, principalmente em relação ao atendimento total de esgoto aos municípios atendidos com água, vinculando a uma maior carência nas áreas não urbanas. Deste modo, as comunidades rurais claramente arcam com os ônus da negligência da prestação dos serviços, que pode ser justificada pela dificuldade das companhias de saneamento projetarem um ganho de escala no atendimento de área com menor densidade populacional.

Em uma análise comparativa, os avanços nas regiões Norte e Nordeste no atendimento total e urbano de esgoto não foram suficientes para suprir a lacuna existente entre estas regiões e as regiões mais desenvolvidas como o Sudeste, ou seja, ainda tem muitas carências inerentes que precisam ser atendidas. Outrossim, a maior deficiência na cobertura do atendimento de esgoto está nas regiões Norte e Nordeste, bem como em áreas rurais.

Entre 2010 e 2017, o IDH avançou e em grande parte das UFs brasileiras atingiu o nível de bom. Ampliando a avaliação das condições de vida da população, incluindo os serviços de água e esgoto pode-se notar um quadro mais complexo. Em linhas gerais, podemos verificar que as disparidades de atrasos no atendimento de água e esgoto permitem melhorar o quadro sobre a qualidade de vida nas regiões brasileira medido pelo IDH e apontar para desigualdades ainda maiores.

\section{REFERÊNCIAS}

BRASIL. Lei no 11.445, de janeiro de 2007. Estabelece as diretrizes nacionais para o saneamento básico; cria o Comitê Interministerial de Saneamento Básico; altera as Leis nos 6.766, de 19 de dezembro de 1979, 8.666, de 21 de junho de 1993, e 8.987, de 13 de fevereiro de 1995; e revoga a Lei no 6.528, de 11 de maio de 1978 (Redação pela Lei no 14.026, de 2020). Brasília: Casa Civil, 2007. Disponível em: https://legislacao.presidencia.gov.br/atos/?tipo=LEI\&numero=11445\&ano=2007\&ato=9bacXWU90MRpWTad7. Acesso em: 25 jun. 2021.

BRASIL. Lei no 9.433, de 8 de janeiro de 1997. Institui a Política Nacional de Recursos Hídricos, cria o Sistema Nacional de Gerenciamento de Recursos Hídricos, regulamenta o inciso XIX do art. 21 da Constituição Federal, e altera o art. 10 da Lei no 8.001, de 13 de março de 1990, que modificou a Lei no 7.990, de 28 de dezembro de 1989. Brasília: Casa Civil, 1997. Disponível em: http://www.planalto.gov.br/ccivil_03/Leis/L9433.htm. Acesso em: 25 jun. 2021.

CERVO, A. L.; BERVIAN, P. A.; SILVA, R. Metodologia Científica. 6.ed., São Paulo: Pearson, 2006.

FGV; TRATA - Fundação Getúlio Vargas; Instituto Trata Brasil. Benefícios Econômicos da Expansão do Saneamento Brasileiro. Brasil, 2010. Disponível em:

http://www.tratabrasil.org.br/datafiles/uploads/estudos/pesquisa7/pesquisa7.pdf. Acesso em: 26 abr. 2021.

HELLER, L. Water and Sanitation Policies in Brazil: Historical Inequalities and Institutional Change. In: CASTRO, J.; HELLER, L. (Ed.). Water and Sanitation Services: Public Policy and Management. Estados Unidos: Earthscan, 2009. p. 321-337.

HERCULANO, S. A qualidade de vida e seus indicadores. Ambiente e Sociedade, ano 1, n. 2, p. 77-99, 1998. 


\section{Revista Científica ANAP Brasil}

ISSN 1984-3240 - Volume 14, número 35, 2021

HERRICK, C. Syndemics of COVID-19 and 'pre-existing conditions'. Sotamosphere, 30 marços 2020. Disponível em: https://www.researchgate.net/publication/340478952_Syndemics_of_COVID-19_and_pre-existing_conditions. Acesso em: 23 abr. 2021.

KUWAJIMA, J. I.; SANTOS, G. R.; FECHINE, V. M. R.; SANTANA, A. S. Saneamento no Brasil: Proposta de Priorização do Investimento Público. Brasília: IPEA, 2020.

MAGNABOSCO, A. L.; FREITAS, F. G. Benefícios Econômicos e Sociais da Expansão do Saneamento Brasileiro. Brasil: Instituto Trata Brasil, 2018. Disponível em: https://sinapse.gife.org.br/download/beneficios-economicos-e-sociaisda-expansao-do-saneamento-brasileiro. Acesso em: 12 mai. 2021.

MARCONI, M. A; LAKATOS, E. M. Fundamentos de metodologia científica. 8.ed., São Paulo: Atlas, 2017.

OMS - Organização Mundial da Saúde. Water, sanitation and hygiene (WASH): Homepage. 2021 Disponível em: https://www.who.int/health-topics/water-sanitation-and-hygiene-wash. Acesso em: 06 jul. 2021.

OMS - Organização Mundial da Saúde. The World Health Organization Quality of Life (WHOQOL- User manual). 2012. Disponível em: https://www.who.int/publications/i/item/WHO-HIS-HSI-Rev.2012.03 . Acesso em: 06 jul. 2021.

OMS - Organização Mundial da Saúde. Constitution of The World Health Organization. 1946. Disponível em: https://apps.who.int/gb/bd/pdf_files/BD_49th-en.pdf . Acesso em: 06 jul. 2021.

ONU - Organização das Nações Unidas. General Comment No. 15: The Right to Water (Arts. 11 and 12 of the Covenant). Geneva: Comissão de direitos econômicos, sociais e culturais, 2002. Disponível em: https://www2.ohchr.org/english/issues/water/docs/CESCR_GC_15.pdf. Acesso em: 22 jun. 2021.

OSTROM, E.; GARDNER, R.; WALKER J.; WALKER, J. Rules, Games, and Common-Pool Resources. University of Michigan Press, 1994.

PNUD, FJP, IPEA. Atlas de Desenvolvimento Humano. Brasil: PNUD, FJP, IPEA [2020]. Disponível em: http://www.atlasbrasil.org.br/consulta. Acesso em: 16 fev. 2021.

RODRIGUES, A. Gestão Hídrica governança dos bens comuns. São Paulo: Editora Origem. 2019.

SEN, A. Desenvolvimento como liberdade. São Paulo: Companhia das Letras, 2010

SNIS - Sistema Nacional de Informações sobre Saneamento. Glossário de Informações - Água e Esgotos - 2018. Versão 29/03/2019. Brasil: Ministério do Desenvolvimento Regional, 2018. Disponível em: http://www.snis.gov.br/glossarios. Acesso em: 14 fev. 2021.

SNIS - Sistema Nacional de Informações sobre Saneamento. Água e esgoto: informações e indicadores agregados. 2018. Brasília: Ministério do Desenvolvimento Regional, Secretaria Nacional de Saneamento. Disponível em: http://app4.mdr.gov.br/serieHistorica/. Acesso em: 16 fev. 2021.

SNIS - Sistema Nacional de Informações sobre Saneamento. SNIS, 5 mar. 2020. Disponível em: http://www.snis.gov.br/institucional. Acesso em: 28 jun. 2021.

UNDP - United Nations Development Programme. Human Development Indices and Indicators 2018 Statistical Update. Nova York, 2018. Disponível em:

http://hdr.undp.org/sites/default/files/2018_human_development_statistical_update.pdf. Acesso em: 06 jul. 2021.

WMO - World Meteorological Organization. The Dublin Statement on Water and Sustainable Development. International Conference on Water and the Environment, 1992. Disponível em:

http://www.wmo.int/pages/prog/hwrp/documents/english/icwedece.html. Acesso em: 25 de fev. 2020.

ZUFFO, A. C.; ZUFFO, M. S. R. Gerenciamento de recursos hídricos: Conceituação e Contextualização. 1.ed., Rio de Janeiro: Elsevier, 2016. 